\title{
Comparison of birth weights of neonates of mothers receiving vs. not receiving zinc supplement at pregnancy
}

\author{
Hassan Boskabadi ${ }^{1}$ D, Gholamali Maamouri', Javad Akhondian', Farah Ashrafzadeh', Abbas Boskabadi', \\ Raheleh Faramarzi ${ }^{1}$, Elahe Heidar ${ }^{1}$, Nafiseh Pourbadakhshan'1, Seyed Reza Habibzadeh Shojaei ${ }^{2}$, \\ Maryam Zakerihamidi ${ }^{3 *}$, Atiyeh Mohammadzadeh Vatanchi ${ }^{4}$, Mohammad Sokhtanloo ${ }^{5}$, Naghmeh Razaghi ${ }^{6}$, \\ Farnaz Kalani ${ }^{7}$, Hosein Ataei ${ }^{7}$, Azadeh Darabi ${ }^{7}$, Mojgan Sadat Mousavi ${ }^{4}$, Saeideh Hakimiakhangan ${ }^{8}$ and \\ Fathemeh Bagheri ${ }^{9}$
}

\begin{abstract}
Background: Zinc is an essential element for normal embryogenesis and embryonic and neonatal development. Therefore, we compared the birth weights of neonates born to mothers who consumed zinc supplement during pregnancy with that of neonates born to mothers who did not.

Methods: In a cross-sectional study, we divided 200 pregnant mothers into two groups: case group (mothers receiving zinc supplement during pregnancy) and control group (mothers not receiving zinc supplement during pregnancy) Then, the neonate's cord zinc level and mother's serum level were measured and neonate's growth charts (weight, height and head circumference)were completed.

Results: In this study, both groups of mothers were observed to have zinc deficiency; 35\% of the mothers who consumed zinc supplements and $81 \%$ of the mothers who did not consume zinc supplements $(P<0.001)$. Based on the results, maternal serum of zinc $(P<0.001)$, neonatal birth weight $(P=0.008)$, maternal age $(P<0.001)$ and parity $(P<0.01)$ in zinc-supplemented group were higher. Neonatal birth weight was associated moderately with mother's zinc serum levels and poorly with neonatal serum zinc levels.
\end{abstract}

Conclusion: Zinc consumption during pregnancy increases serum zinc level of mother and neonatal weight. Neonatal weight has a higher correlation to maternal serum zinc level.

Keywords: Zinc, Pregnancy, Birth weight, Neonate, Supplements

\section{Background}

Birth weight is one of the major determinants of the future development of a child's growth, both physically and neurologically, a valid indicator of intrauterine growth, and an important indicator of neonate health [1]. It is also considered a factor in measuring pregnancy

\footnotetext{
* Correspondence: maryamzakerihamidi@yahoo.co.nz

${ }^{3}$ Department of Midwifery, School of Medical Sciences, Tonekabon Branch, Islamic Azad University, Tonekabon, Iran

Full list of author information is available at the end of the article
}

outcome [2]. This index is related to maternal health, quality of prenatal care, socio-economic factors [3] and maternal nutrition quality [4]. Low birth weight (weight below $2500 \mathrm{~g}$ ) leads to higher mortality, disability, and morbidity in childhood [5].

Pregnancy is associated with an increase in the need for micronutrients, including zinc, and a decrease in these can affect the prognosis of pregnancy [6, 7]. Zinc plays an important role during embryogenesis and embryo development. Therefore, the need for zinc during

(c) The Author(s). 2021 Open Access This article is licensed under a Creative Commons Attribution 4.0 International License, which permits use, sharing, adaptation, distribution and reproduction in any medium or format, as long as you give appropriate credit to the original author(s) and the source, provide a link to the Creative Commons licence, and indicate if changes were made. The images or other third party material in this article are included in the article's Creative Commons licence, unless indicated otherwise in a credit line to the material. If material is not included in the article's Creative Commons licence and your intended use is not permitted by statutory regulation or exceeds the permitted use, you will need to obtain permission directly from the copyright holder. To view a copy of this licence, visit http://creativecommons.org/licenses/by/4.0/ The Creative Commons Public Domain Dedication waiver (http://creativecommons.org/publicdomain/zero/1.0/) applies to the data made available in this article, unless otherwise stated in a credit line to the data. 
pregnancy is greater. Increased dietary zinc and zinc uptake, reduced zinc loss, and altered zinc production in the body can lead to increased body zinc requirement in pregnancy [8]. Walt et al. stated that providing nutritional supplements during pregnancy is essential for fetal growth, and that deficiencies in vitamins and minerals, especially folic acid, vitamin B12, calcium, iron and zinc, are associated with adverse pregnancy outcomes and has negative side effects on fetal health, growth and development [9]. Zinc deficiency has also been associated with neonatal jaundice [10]. However, Zinc consumption in newborns has not been shown to decrease the incidence and severity of jaundice [11].

During pregnancy, due to a higher number of red blood cells, embryonic growth and placenta formation, maternal need for supplements is increased. If supplements are inadequate, contrastingly, increased maternal plasma volume and physiological anemia in pregnancy can lead to an inadequate oxygen supply and trace elements for the embryo; and this, in turn, may interfere with fetal growth. Given the high cost of caring for low birthweight neonates and their consequent health issues, postpartum care for these neonates has been the focus of researchers for decades with the intent of improving their prenatal care conditions [12]. The present study objective is to compare the birth weights of neonates whose mothers consumed zinc supplement in pregnancy with the weight of those whose mothers did not.

\section{Methods}

\section{Study design and population}

This cross-sectional study was carried out on neonates born from 2016 to 2019 to 109 (66.1\%) mothers who did not use zinc supplement during pregnancy (control group) and 56 (33.9\%) mothers who used zinc supplement during pregnancy (case group). After obtaining the approval of ethics committee and the code 950082, from Mashhad University of Medical Sciences)IR.MUMS. fm.REC.1395.238(, and obtaining informed written consent from pregnant mothers. Mothers with a gestational age of more than 37 weeks who presented labor pains were assessed for zinc supplementation. Mothers with a history of at least 3 months of zinc intake, at least $25 \mathrm{mg}$ daily, were included in the study and mothers with a history of not using zinc supplements were considered as the control group. According to Saaka et al. study, zincsupplemented mothers had a $60 \%$ increase in serum zinc levels, while the non-zinc supplemented mothers had a $30 \%$ increase in serum zinc levels. In our study, we used the formula of comparing two ratios related to an attribute from two communities and $\alpha=0.05$ and $\beta=$ $0.2=$ sample size. A minimum of 56 people was included in each group [13].

\section{Inclusion and exclusion criteria}

Inclusion criteria included live neonates over 37 weeks of gestation born to apparently healthy mothers with single pregnancy. Exclusion criteria included the following; mothers who did not use zinc regularly (no more than 2 days a week), mothers with specific underlying disease (preeclampsia, gastrointestinal diseases, hypertension, infections, malignancy, bone and endocrine disorders, history of anticonvulsant and neurologic medication use),mothers with multiple newborns, or very ill neonates who died within the first $24 \mathrm{~h}$, neonates with severe asphyxia, cases with incomplete information, and probability of infection in the sampling tube.

\section{Anthropometric measures}

Data was collected through checklists and face-to-face interviews with mothers, review of maternal and neonatal medical records, and a neonatal examination by a neonatologist. For neonates in our study, information including sex, gestational age, birth weight, head circumference and height, as well as maternal information including maternal age, parity, type of delivery and zinc supplement consumption was gathered and recorded. All neonates were weighed at birth by a midwife using the Misaki Balance made in Japan with $50 \mathrm{~g}$ accuracy; head circumference and height were also measured. Neonates of less than $2500 \mathrm{~g}$ are defined as low birth weight (LBW).

\section{Biochemical measures}

At birth, the neonate's umbilical blood cord is usually discarded and about $2 \mathrm{cc}$ of blood is collected from mother simultaneously. The serum is separated and sent to a laboratory in dark or coated tubes to measure the zinc content. Before sampling, the serum tubes were thoroughly rinsed with acid and deionized water to remove trace elements and after $10 \mathrm{~min}$ the serum was centrifuged $(1000 \mathrm{rpm})$ in polyethylene tubes. Serums were obtained from both groups and kept in a freezer at - 70 degrees Celsius. After unfreezing, all serum samples were diluted by $1 \%$ nitric acid. Zinc level was measured by atomic absorption spectrophotometer (Perkin-Elmer 2380; Perkinelmer, Wellesly, MA, USA) through preparing suitable calibration graphics of wavelengths for each parameter. Mothers and neonates with zinc levels below $60 \mu \mathrm{g} / \mathrm{dl}$ were considered zinc deficient.

\section{Statistical methods}

After collecting and recording the data in SPSS Software (version 23 SPSS Inc., Chicago, Illinois, USA), we examined it using tables, graphs, and statistical indicators. First, the distribution status of the variables was investigated using the Kolmogorov-Smirnov test. For comparing the mean of quantitative variables between the 
groups, independent t-test or nonparametric equivalent, Mann-Whitney test, was used. For comparison of the qualitative variables between the studied groups, chisquare test was used. Spearman and Pearson correlations were used to determine the correlation serum zinc level of mothers \& neonates, and birth weight $P$-value of less than 0.05 was regarded as statistically significant.

\section{Results}

Of the 200 mothers studied, 16 infants with improper zinc supplement use, 8 neonates requiring resuscitation in the operating room, 6 neonates requiring hospitalization in the first week, and 5 samples due to probability of tube contamination were excluded. In this study, 56 (33.9\%) of pregnant mothers used zinc supplement (case group) and 109 (66.1\%) pregnant mothers did not (control group). One hundred and two neonates $(61.8 \%)$ were born by cesarean section and 63 neonates (38.2\%) by vaginal delivery. Seventy-six neonates $(51.4 \%)$ were male and seventy-two neonates $(48.6 \%)$ were female. Serum zinc levels in $60 \%$ of mothers and $33 \%$ of neonates were less than $60 \mu \mathrm{g} / \mathrm{dl}$. Eighty-one percent of mothers who had not consumed zinc supplement during pregnancy had zinc deficiency, while 35\% of mothers consuming zinc supplement had deficiency during pregnancy $(P<0.001)$.Zinc deficiency was seen in $31 \%$ of neonates of mothers who had not consumed zinc supplement during pregnancy, and in $28 \%$ of neonates of mothers who had consumed zinc supplement during pregnancy $(P=0.221)$.

Both mothers of neonates weighing less than $2500 \mathrm{~g}$ and mothers of neonates weighing more than $2500 \mathrm{~g}$; $70 \%$ and $28 \%$ respectively, were found to have deficiency of zinc $(P<0.001)$. Thirty-seven percent of neonates weighing less than $2500 \mathrm{~g}$ and $33 \%$ of neonates weighing more than $2500 \mathrm{~g}$ had zinc deficiency $(P=0.427)$.

In this study, there were significant differences in maternal serum zinc level $(P<0.001)$, birth weight $(P=$ $0.008)$, maternal age $(P<0.001)$ and parity $(P=0.001)$ between the two groups of neonates, namely, those born to mothers with zinc supplement intake and those born to mothers without it. These results confirm that the values of these variables were higher in neonates with zinc-supplemented mothers. There was no significant difference between the two groups of neonates in neonatal serum zinc level $(P=0.626)$, head circumference $(P=0.193)$ and height $(P=0.313)$ (Table 1$)$.

The difference between the two groups in terms of sex $(P=0.398)$ and gestational age $(P=0.474)$ was not statistically significant. The results show that birth weight is moderately correlated with maternal serum zinc and poorly correlated with neonatal serum levels (Table 2, Fig. 1, 2).

\section{Discussion}

Sixty percent of mothers and 33\% of neonates had zinc levels lower than $60 \mu \mathrm{g} / \mathrm{dl}$. In this study, one-third of pregnant women used zinc supplements during pregnancy. Although severe zinc deficiency is relatively rare, mild to moderate zinc deficiency is very common. It is estimated that about $59.9 \%$ of pregnant women and $38.4 \%$ of children have zinc deficiency [14]. Recent estimates have shown that about half a million deaths of mothers and children due to zinc deficiency occur annually worldwide, which raises widespread concerns about insufficient zinc intake by pregnant women in developing countries [15]. It is also estimated that approximately $50 \%$ of women of reproductive age suffer from zinc deficiency. Zinc deficiency in mother's serum reduces zinc transfer to the fetus and increases the risk of developmental defects. It plays important structural and enzymatic roles in many proteins. Part of the teratogenic effects of zinc deficiency may be due to alterations in the activity of proteins in the fetus [16].

Seventy percent of mothers of LBW infants had zinc levels less than $60 \mu \mathrm{g} / \mathrm{dl}$ while $28 \%$ of mothers of neonates weighing more than $2500 \mathrm{~g}$ had zinc levels less than $60 \mu \mathrm{g} / \mathrm{dl}(P<0.001)$. According to the results of

Table 1 Comparison of the maternal and neonate background characteristics between neonates with mothers without zinc supplement and neonates with mothers with zinc supplement

\begin{tabular}{|c|c|c|c|}
\hline Variable & $\begin{array}{l}\text { Neonates with maternal zinc supplement } \\
56 \text { Neonates(33/9\%) } \\
\text { mean } \pm \text { SD }\end{array}$ & $\begin{array}{l}\text { Neonate without maternal zinc supplement } \\
109 \text { Neonates }(66 / 1 \%) \\
\text { mean } \pm \text { SD }\end{array}$ & $P$-Value (T-Test) \\
\hline $\begin{array}{l}\text { serum zinc level of Mother } \\
(\mu \mathrm{g} / \mathrm{dl})\end{array}$ & $68 / 36 \pm 17 / 17$ & $50 / 82 \pm 17 / 42$ & $0 / 000$ \\
\hline Neonatal serum zinc level $(\mu \mathrm{g} / \mathrm{dl})$ & $64 / 95 \pm 21 / 62$ & $62 / 61 \pm 17 / 65$ & $0 / 626$ \\
\hline Birth weight (gr) & $3096 / 50 \pm 577 / 55$ & $2828 / 28 \pm 617 / 84$ & 0/008 \\
\hline Head circumference (cm) & $34 / 26 \pm 2 / 62$ & $33 / 55 \pm 2 / 09$ & 0/193 \\
\hline Height (cm) & $49 / 04 \pm 3 / 82$ & $48 / 18 \pm 3 / 41$ & $0 / 313$ \\
\hline Maternal age (year) & $35 / 36 \pm 6 / 01$ & $29 / 62 \pm 6 / 82$ & $0 / 000$ \\
\hline Parity & $3 / 00 \pm 1 / 53$ & $2 / 08 \pm 1 / 17$ & 0/001 \\
\hline
\end{tabular}


Table 2 comparison of relationship between birth weight and maternal and neonatal serum level

\begin{tabular}{|c|c|c|c|}
\hline Variant & Paired Samples Correlations & $\begin{array}{l}\text { Paired Samples Correlations (Pearson) } \\
\text { Sig. }\end{array}$ & Mean \pm Standard deviation \\
\hline Birth weight (gr) & $0 / 311$ & $0 / 002$ & $55 / 577 \pm 50 / 3096$ \\
\hline Maternal zinc level ( $\mu \mathrm{g} / \mathrm{dl})$ & & & $17 / 17 \pm 36 / 68$ \\
\hline Birth weight (gr) & 0/074 & $0 / 378$ & $55 / 577 \pm 50 / 3096$ \\
\hline Neonatal zinc level $(\mu \mathrm{g} / \mathrm{dl})$ & & & $62 / 21 \pm 95 / 62$ \\
\hline
\end{tabular}

one study, serum zinc levels were significantly lower in LBW neonates than in normal neonates. Zinc levels were also lower in mothers of LBW neonates as compared to mothers of neonates with optimum birth weight. Low maternal zinc levels are associated with low zinc levels in LBW neonates [17]. Gupta found that zinc levels in the serum of Small for Gestational Age (SGA) neonates is lower than neonates with appropriate weight. It has also been shown that zinc deficiency is more common in preterm SGA newborns. SGA neonates have significant zinc deficiency as compared to AGA neonates. This zinc deficiency is even more pronounced in SGA newborns that are born preterm. Therefore, use of zinc supplementation during pregnancy especially for preterm and SGA babies can promote positive outcomes of maternal and child health [18].

According to the results of this study, $81 \%$ of mothers who had not consumed zinc supplement during pregnancy had zinc levels lower than $60 \mu \mathrm{g} / \mathrm{dl}$ while $35 \%$ of mothers having consumed zinc had zinc levels lower than $60 \mu \mathrm{g} / \mathrm{dl}$ during pregnancy $(P<0.001)$. Gholizadeh showed that high concentration of zinc in mother's serum was directly associated with dietary intake zinc and supplement zinc. Hanachi indicated that the zinc deficiency in the latter third of pregnancy may suggest insufficient maternal nutrition [19]. There are no valid tools for measuring nutrition zinc adequacy. This evaluation is difficult because of the fact that all digested zinc is not consumed by the organism and its bioavailability may be affected by intestinal absorption or blood circulation. Intestinal absorption may be reduced by dietary antagonistic factors such as phytates, oxalates, tannins, and polyphenols, while circulating zinc may compete with copper and iron, depending on the amount of these elements in the bloodstream [20]. Lack of response to zinc supplement intake (lack of proper serum increase) may be due to lack of gestational age control or serum albumin concentration or low sample size. Despite these

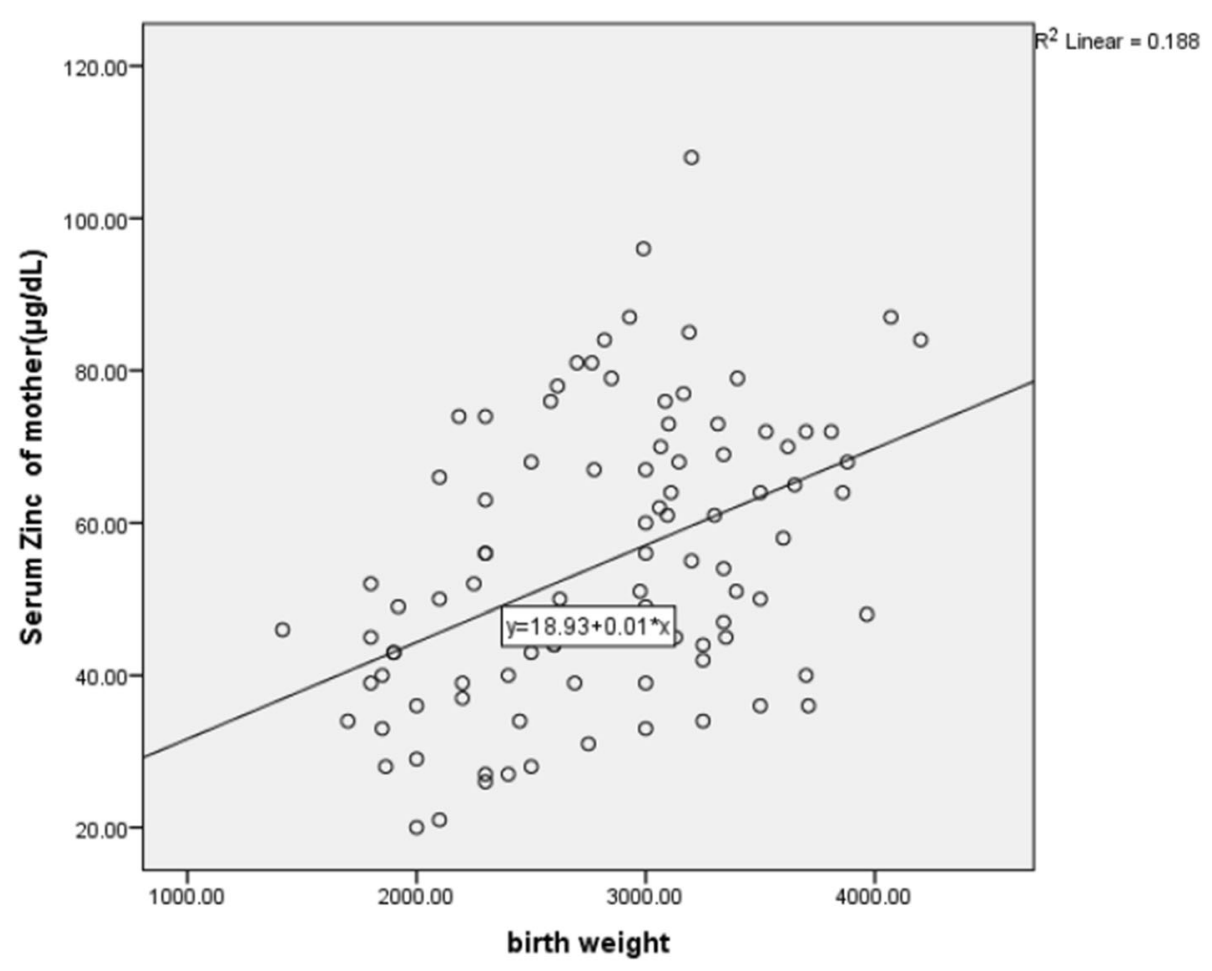

Fig. 1 Relationship between birth weight and maternal serum zinc 


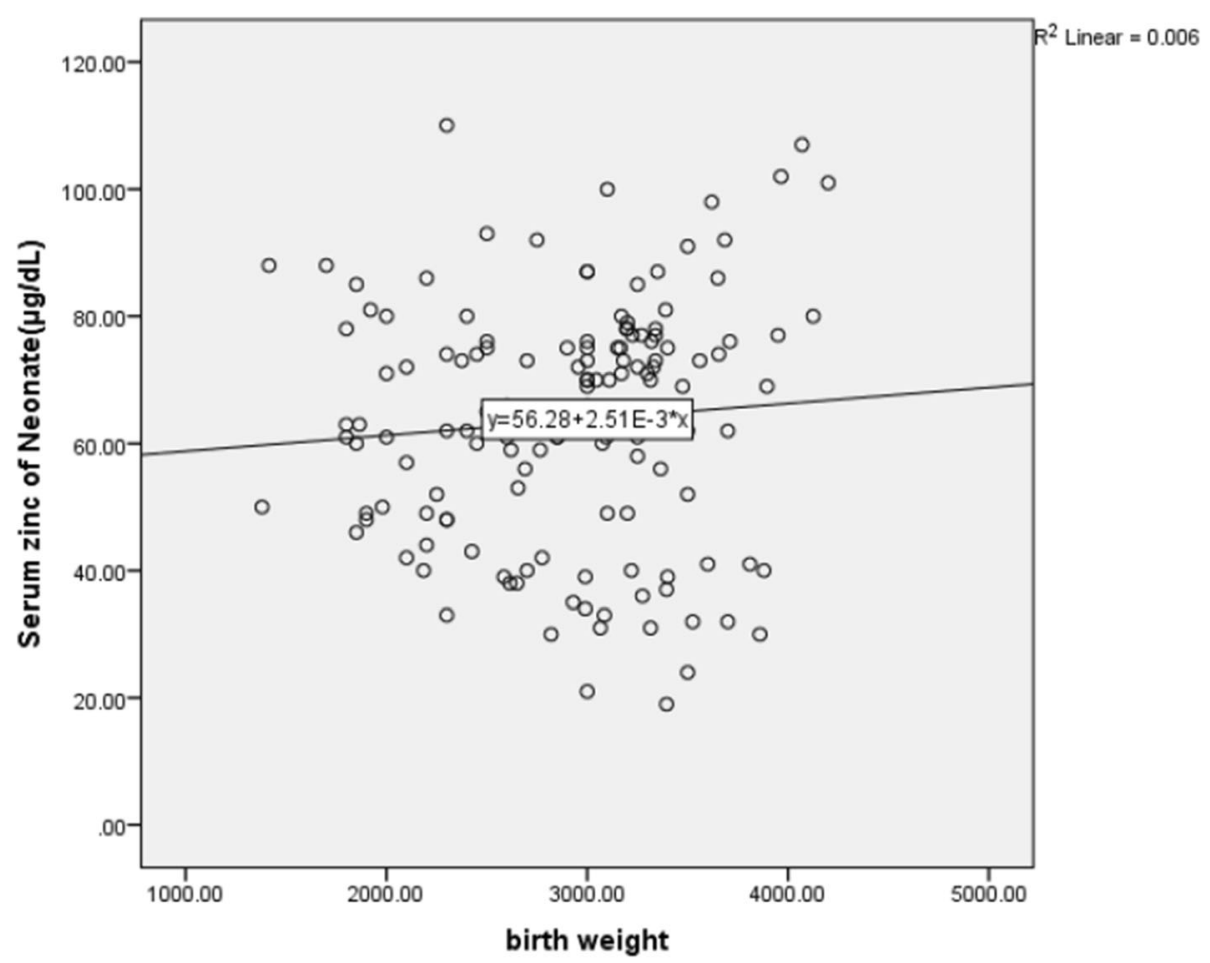

Fig. 2 Relationship between birth weight and neonatal serum level

limitations, serum zinc concentration is currently used as a biochemical indicator of zinc status during pregnancy and is an indicator to evaluate the effect of zinc supplement in pregnant women [21].

According to the results of our study, $31 \%$ of neonates of mothers who did not use zinc during pregnancy had a zinc level less than $60 \mu \mathrm{g} / \mathrm{dl}$ while $28 \%$ of neonates of mothers who consumed zinc during pregnancy had a zinc level less than $60 \mu \mathrm{g} / \mathrm{dl}(P=$ 0.221). Placental transfer and release into the baby's blood is an active process. The concentration of zinc in the umbilical cord serum was $14 \mu \mathrm{mol} / \mathrm{L}$ and the concentration of zinc in the mother serum was 6 to $15.6 \mu \mathrm{mol} / \mathrm{L}$ [22].

Therefore, zinc deficiency in neonates occurs only in cases of severe zinc deficiency in the mother and due to the function of placental transfer of zinc to the fetus, neonatal zinc levels are usually higher than the mother's zinc levels [8]. Possibly due to the transfer of the mother's zinc stores to neonates, zinc levels did not decrease among neonates of mothers not consuming zinc, similar to the group of neonates whose mothers did consume zinc.

In this study, serum zinc levels of mothers receiving zinc supplement were higher $(P<0.001)$. Zinc levels during pregnancy are affected by dietary zinc intake. Physiological changes in zinc metabolism in pregnancy include changes in the tissue distribution of zinc in the body, increased zinc uptake, decreased endogenic zinc loss, and changes in zinc production [8].

In one study, a higher zinc supplement of $25 \mathrm{mg} /$ day was given to mothers. Zinc concentration in maternal plasma was evaluated. It declined during pregnancy irrespective of using zinc supplements. This supplement increased zinc levels in maternal erythrocyte as compared to women not using zinc supplements [22]. In another study, the neonatal zinc level was higher than their mothers. It seems placental transfer and release into the baby's blood is an active process as a result of high zinc requirement in the fetus. On the other hand, it could be caused by increased absorption in the fetus and reduction of maternal zinc during pregnancy due to physiologic dilution of maternal blood volumes [6].Therefore, it seems reasonable that zinc consumption in the mother would lead to an increase in maternal serum levels.

Birth weight of neonates consuming zinc supplement was higher $(P=0.008)$. According to the results of this study, the birth weight of neonates had a moderate correlation with maternal serum zinc level and a weak correlation with neonatal serum zinc level. Low concentrations of zinc in the mother's serum reduce placental transfer to the fetus. Therefore, the use of multivitamin supplements containing zinc is recommended to all pregnant women in developing countries since zinc 
supplement significantly improves weight gain and growth in children. However, other factors (nutritional and environmental) can also contribute to child growth [23].

Based on the results of one study, maternal zinc supply in mid-pregnancy from animal sources was positively correlated with neonatal birth weight and height [24]. Results of another study showed that prenatal iron and zinc supplement may increase neonatal birth weight in anemic and iron deficient mothers, but in mothers with high iron stores early in pregnancy, these supplements may not affect neonatal birth weight [13]. A researcher in Tanzania found that mothers who had low levels of zinc at birth had a two-and-a-half-fold increase in the likelihood of having babies weighing less than $2000 \mathrm{~g}$ compared to mothers with normal zinc levels [25]. In Kadem's study, zinc supplement intake by pregnant women had a positive effect on birth weight and head circumference [26]. Maamouri et al. showed that there was a relationship between birth weight below $2500 \mathrm{~g}$ and maternal zinc level and that the risk of having babies weighing less than $2500 \mathrm{~g}$ is 3.8 times higher in mothers with zinc levels less than $6.4 \mathrm{~mol} / \mathrm{l}$ [6]. As our study shows, consuming zinc in the mother significantly increases the birth weight and may reduce the birth of LBW neonates.

\section{Conclusion}

The results of the present study showed that one third of pregnant women use zinc supplement. Two-thirds of mothers of LBW neonates and four-fifths of mothers who had not consumed zinc supplement during pregnancy had zinc levels lower than $60 \mu \mathrm{g} / \mathrm{dl}$, while one third of mothers consuming zinc supplement during pregnancy had zinc levels less than $60 \mu \mathrm{g} / \mathrm{dl}$. Although zinc consumption by mothers did not significantly increase serum Zinc level of newborn, it did increase the neonates' weight. Furthermore, birth weight had stronger correlation with mothers' Zinc levels than with newborns' Zinc levels. Concerning the importance of birth weight in neonates' mortality and complications, Zinc consumption by mothers might improve the weight of these newborns and supplementation of zinc (as well as other micronutrients) should be considered essential..

\section{Abbreviations}

LBW: Low birth weight; SGA: Small for Gestational Age

\section{Acknowledgements}

We would like to thank all people who helped us in this project.

\section{Authors' contributions}

$H B, G h M, J A, F A, A B, R f$, contributed to the conception and design of the research; Eh, NP, RHSh,MZ, contributed to the design of the research; AMV, MS, NR, Fk, HA, Ad, MSM, SH,FB contributed to the acquisition and analysis of the data; NR contributed to the interpretation of the data; and Fk, HA, Ad drafted the manuscript. All authors critically revised the manuscript, agree to be fully accountable for ensuring the integrity and accuracy of the work, and read and approved the final manuscript.

Funding

Not Applicable.

Availability of data and materials

If needed, patient data will share. Research data are available within the manuscript and/or additional supporting files. Identifying/confidential patient data should not be shared.

\section{Ethics approval and consent to participate}

Ethical approval was obtained from the Ethics Committee of Mashhad University of Medical Sciences. Parents' informed written consent was obtained before entering the study.

\section{Consent for publication}

We have obtained consent to publish from each patient.

\section{Competing interests}

The authors declare that they have no competing interests.

\section{Author details}

${ }^{1}$ Department of Pediatrics, Faculty of Medicine, Mashhad University o Medical Sciences, Mashhad, Iran. ${ }^{2}$ Department of Orthopedic Surgeon, Faculty of Medicine, Faculty of Medicine, Mashhad University of Medical Sciences, Mashhad, Iran. ${ }^{3}$ Department of Midwifery, School of Medical Sciences, Tonekabon Branch, Islamic Azad University, Tonekabon, Iran. ${ }^{4}$ Department of Gynecology, Faculty of Medicine, Mashhad University of Medical Sciences, Mashhad, Iran. ${ }^{5}$ Department of Biochemistry, Faculty of Medicine, Mashhad University of Medical Sciences, Mashhad, Iran. ${ }^{6}$ Nursing and Midwifery Care Research Center, Mashhad University of Medical Sciences, Mashhad, Iran. ${ }^{7}$ Department of Pediatrics, Fellowship of neonatology, Mashhad University of Medical Sciences, Mashhad, Iran. ${ }^{8}$ Neonatal Intensive Care, Faculty member of Mashhad University of Medical Sciences, Mashhad, Iran. ${ }^{9}$ Neonatal Intensive Care, Faculty member of Azad University, Mashhad, Iran.

Received: 28 April 2020 Accepted: 27 January 2021

Published online: 06 March 2021

\section{References}

1. Alexander G, Wingate M, Mor J, Boulet S. Birth outcomes of Asian-IndianAmericans. Int J Gynecol Obstet. 2007;97(3):215-20.

2. Eftekhar $\mathrm{H}$, Agha Moulaei T, Abedini S. Risk factors associated with intrauterine growth retardation (IUGR) in Bandar Abbas, Iran. Payesh. 2007; 6(3):201-8.

3. Kramer MS, Barros FC, Demissie K, Liu S, Kiely J, Joseph K. Does reducing infant mortality depend on preventing low birthweight? An analysis of temporal trends in the Americas. Paediatr Perinat Epidemiol. 2005:19(6):445-51.

4. Zeyghami B, Tabatabaei S, Parisal Z. A study on correlation of mother's risk factors with low birth weight of newborns at a multiple regression model in Kohghiloyeh and Boyerahmad province in 2004-2005. Armaghane Danesh J Yasuj University Med Sci. 2005;40(10):37-45.

5. Mansour E, Eissa A, Nofal L, Kharboush I, Reda A. Morbidity and mortality of low-birth-weight infants in Egypt. East Mediterr Health J. 2005;11(4):723-31.

6. Maamouri G, Boskabadi H, Noria M, Ayatollahi H, Ghayour-Mobarhan M, Heshmati A, et al. Maternal and neonatal zinc and copper levels and birth weight. Iran J Neonatol. 2011;2(1):26-31.

7. Boskabadi H, Maamouri G, Nori M, Mohsenzadeh H, Ayatollahi H, GhayourMobarhan M, et al. Maternal and neonatal serum concentrations of zinc and copper in preterm delivery: an observational study. Trace Elements Electrolytes. 2012;29(4):232

8. Donangelo CM, King JC. Maternal zinc intakes and homeostatic adjustments during pregnancy and lactation. Nutrients. 2012;4(7):782-98.

9. Van der Walt D. Dietary intake and pregnancy outcome of pregnant women in an outpatient clinic: North-West University; 2005.

10. Boskabadi H, Maamouri G, Mohsen Zadeh H, Shakeri MT, GhayourMobarhan M, Mohammadi S, et al. Comparison of serum zinc level between 
neonates with jaundice and healthy neonates. Shiraz E-Med J. 2015;16(11, 12):e27392.

11. Maamouri G, Boskabadi H, Mafinejad S, Bozorgnia Y, Khakshur A. Efficacy of oral zinc sulfate intake in prevention of neonatal jaundice. Iran J Neonatol. 2014;4(4):11-6.

12. Mardazad N, Nahidi F, Jannasari S, Amiri Z. Assessment of effect of mother consulting on weighting of low birth weight neonate jentashapir 2012;3(3): 417-426.

13. Saaka M, Oosthuizen J, Beatty S. Effect of prenatal zinc supplementation on birthweight. J Health Popul Nutr. 2009;27(5):619.

14. Berhe K, Gebrearegay F, Gebremariam H. Prevalence and associated factors of zinc deficiency among pregnant women and children in Ethiopia: a systematic review and meta-analysis. BMC Public Health. 2019;19(1):1663.

15. Black RE, Allen LH, Bhutta ZA, Caulfield LE, De Onis M, Ezzati M, et al. Maternal and child undernutrition: global and regional exposures and health consequences. Lancet. 2008;371(9608):243-60.

16. Hanna LA, Clegg MS, Ellis-Hutchings RG, Niles BJ, Keen CL. The influence of gestational zinc deficiency on the fetal insulin-like growth factor axis in the rat. Exp Biol Med. 2010;235(2):206-14.

17. Jyotsna S, Amit A, Kumar A. Study of serum zinc in low birth weight neonates and its relation with maternal zinc. J Clin Diagn Res. 2015;9(1): SC01.

18. Gupta N, Bansal S, Gupta M, Nadda A. A comparative study of serum zinc levels in small for gestational age babies and appropriate for gestational age babies in a tertiary hospital, Punjab. J Fam Med Prim Care. 2020;9(2):933.

19. Hanachi P, Norrozi M, Moosavi RM. The correlation of prenatal zinc concentration and deficiency with anthropometric factors. J Family Reprod Health. 2014;8(1):21.

20. Fernandes Cruz JB, Freire SH. Uma revisão sobre o zinco. Ensaios Ciência. 2011;15(1):207-22.

21. De Benoist B, Darnton-Hill I, Davidsson L, Fontaine O, Hotz C. Conclusions of the joint WHO/UNICEF/IAEA/IZiNCG interagency meeting on zinc status indicators. Food Nutr Bull. 2007;28(3_suppl3):S480-S4.

22. Caulfield LE, Donangelo CM, Chen P, Junco J, Merialdi M, Zavaleta N. Red blood cell metallothionein as an indicator of zinc status during pregnancy. Nutrition. 2008:24(11-12):1081-7.

23. Roohani N, Hurrell R, Kelishadi R, Schulin R. Zinc and its importance for human health: an integrative review. J Res Med Sci. 2013;18(2):144.

24. Lee YA, Hwang J-Y, Kim H, Ha E-H, Park H, Ha M, et al. Relationships of maternal zinc intake from animal foods with fetal growth. Br J Nutr. 2011; 106(2):237-42

25. Rwebembera AA-B, Munubhi E, Manji K, Mpembeni R, Philip J. Relationship between infant birth weight $\leq 2000 \mathrm{~g}$ and maternal zinc levels at Muhimbili National Hospital, Dar Es Salaam, Tanzania. J Trop Pediatr. 2005;52(2):118-25.

26. Khadem N, Mohammadzadeh A, Farhat A, Valaee L, Khajedaluee M, Parizadeh S. Relationship between low birth weight neonate and maternal serum zinc concentration. Iran Red Crescent Med J. 2012;14(4):240.

\section{Publisher's Note}

Springer Nature remains neutral with regard to jurisdictional claims in published maps and institutional affiliations.

Ready to submit your research? Choose BMC and benefit from:

- fast, convenient online submission

- thorough peer review by experienced researchers in your field

- rapid publication on acceptance

- support for research data, including large and complex data types

- gold Open Access which fosters wider collaboration and increased citations

- maximum visibility for your research: over $100 \mathrm{M}$ website views per year

At $\mathrm{BMC}$, research is always in progress.

Learn more biomedcentral.com/submissions 